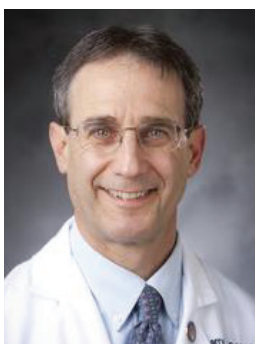

\title{
MODERN MEDICAL MANAGEMENT OF ACUTE ISCHEMIC STROKE
}

\author{
Larry B. Goldstein, M.D. \\ Duke University Medical Center and Durham VA Medical Center, Durham, NC
}

\begin{abstract}
The modern management of patients with ischemic stroke begins by having a system in place that organizes the provision of preventive, acute treatment, and rehabilitative services. In the acute setting, initial evaluation is aimed at rapidly establishing a diagnosis by excluding stroke mimics, distinguishing between ischemic and hemorrhagic strokes, and determining if the patient is a candidate for treatment with intravenous tissue plasminogen activator (IV-tPA, alteplase). In some centers, select patients who do not qualify for administration of IV-tPA may be considered for endovascular intervention. General measures include the use of platelet antiaggregants, treatment of fever, blood pressure management, and continuation of statins if the patient has already been taking them. Post-acute evaluation and management is aimed at secondary prevention and optimizing recovery, including recognition and treatment of post-stroke depression.
\end{abstract}

\section{Introduction: Organizing Acute Stroke Care}

The modern medical management of patients with acute ischemic stroke focuses on limiting the extent of brain injury, avoiding stroke-related complications, instituting appropriate secondary prevention, and facilitating post-stroke recovery. Given the time-sensitive nature of acute-stroke therapy, having an organized system of care is critical. An American Heart Association policy statement highlights the importance of stroke care systems beginning with primordial prevention and extending to primary prevention, prehospital care, treatment related to the acute event, and post-stroke rehabilitation and community reintegration. ${ }^{1}$ Primary Stroke Centers that emphasize care in the acute setting and initiation of secondary preventive interventions have been established across the country, with certification by the Joint Commission or other groups based on demonstration of compliance with recommendations from the Brain Attack Coalition and American Heart Association guidelines. ${ }^{2,3}$ Comprehensive Stroke Centers, capable of providing the full range of strokerelated care for patients with complex cerebrovascular conditions and for those who might benefit from advanced interventions, are also being certified. ${ }^{4}$ Although many noncertified hospitals have excellent patient outcomes, care at hospitals with certified stroke centers is generally associated with lower mortality rates as compared to noncertified hospitals. ${ }^{5-7}$ Participation in quality improvement efforts such as the American Heart Association Get with the Guidelines program or the Coverdale National Stroke
Registry is associated with incremental improvements in compliance with evidence-based, guideline-recommended treatments over time. ${ }^{8}$ Having the appropriate infrastructure is a necessary prerequisite for optimizing the process of stroke care and patient outcomes.

\section{Initial Evaluation}

Figure 1 provides an example of one general algorithm outlining the approach to evaluating and treating patients with acute ischemic stroke. Different hospitals may reasonably vary their practices, and involvement in research protocols may further alter this evaluation and management paradigm.
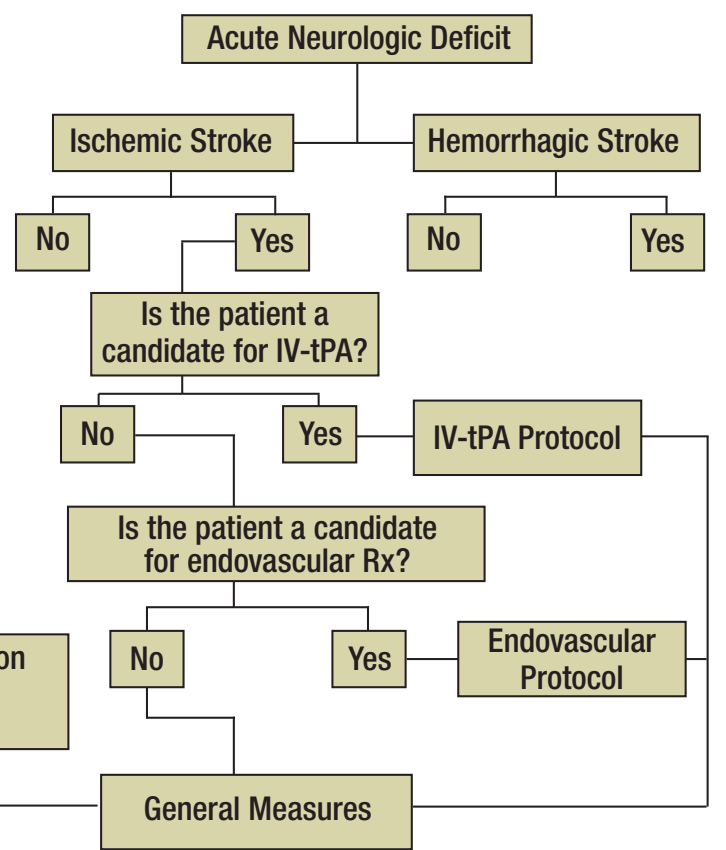

Figure 1. Example algorithm outlining one approach to the management and evaluation of patients with symptoms of an acute ischemic stroke.

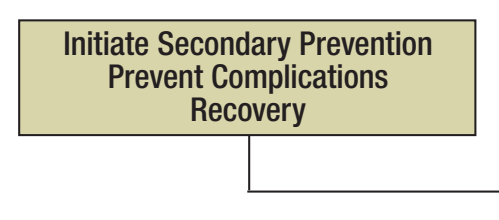

General Measures 
The presence of acute facial paresis, arm drift, or abnormal speech increases the likelihood of stroke 5.5-fold (95\% CI, 3.3-9.1). ${ }^{9}$ Although presentation with acute, focal neurologic deficits is the hallmark of stroke, initial symptoms can vary. Many patients, particularly women, have nontraditional symptoms such as generalized weakness, fatigue, and cognitive change that can make rapid diagnosis challenging. ${ }^{10,11}$ Common stroke mimics include seizures, sepsis, space-occupying lesions, and toxic/ metabolic conditions. ${ }^{12}$ Even in patients who have had a stroke, distinguishing between ischemic and hemorrhagic causes is critical. Although certain clinical features increase the likelihood of hemorrhagic stroke (e.g., initial depressed level of consciousness, vomiting, severe headache, warfarin therapy, systolic blood pressure $>220 \mathrm{~mm} \mathrm{Hg}$, and glucose $>170 \mathrm{mg} / \mathrm{dL}$ in a patient without diabetes), the accuracy of discriminant models is similar to clinician judgment, with neither sufficient for determining treatment. ${ }^{9}$ In addition to basic laboratory studies including blood glucose, oxygen saturation, serum electrolytes/renal function tests, complete blood count including platelet count, cardiac enzymes, prothrombin time, activated partial thromboplastin time, and electrocardiogram, neuroimaging with a brain CT or MRI is required to help exclude stroke mimics and to reliably distinguish ischemic from hemorrhagic stroke. ${ }^{2} \mathrm{~A}$ toxicology screen should be considered and a chest X-ray obtained in those with respiratory symptoms or other specific indications. ${ }^{13}$ Blood tests should be obtained as soon as possible in all patients suspected of having an acute stroke, with the goal of having results available within 45 minutes. $^{2}$

After assuring the integrity of the patient's airway, oxygenation, and circulatory status, a history is obtained and rapid general and neurological examinations are performed with an immediate goal of determining the appropriateness of acute reperfusion therapy. This should include a standardized, reliable, and validated graded neurologic score that can be used to help determine the risks and benefits of interventions, to aid in estimating prognosis, ${ }^{14}$ and for communicating with other clinicians. The National Institutes of Health Stroke Scale is among those most commonly used for these purposes. ${ }^{15}$

\section{Acute Reperfusion Therapy}

Treatment with acute reperfusion therapy is based on the principle that whether a given area of ischemic brain tissue becomes irreversibly damaged (i.e., infarcted) depends on both the degree and duration of ischemia. ${ }^{16}$ Administration of alteplase (IV-tPA) within 3 hours of symptom onset is currently the only treatment for acute ischemic stroke approved by the U.S. Food and Drug Administration (FDA). ${ }^{2}$ Figure $2 \mathrm{~A}$ gives the odds of an excellent outcome (i.e., no functional disability at 90 days) based on a pooled analysis of data from four randomized trials of IV-tPA ( $n=1850)$ compared to placebo $(\mathrm{N}=1820) .{ }^{17}$ Approximately 4.5 patients need to be treated within 1.5 hours, 9 between 1.5 to 3 hours, and 14.1 between 3 to 4.5 hours to have one additional patient with no disability at 90 days. Although national guidelines recommend treatment of selected patients up to 4.5 hours after symptom onset, ${ }^{2}$ the longer the delay between symptom onset and treatment, the less likely the patient will benefit (Figure 2A). ${ }^{17}$ As a result, patients should be treated as soon as possible, and the American Heart Association Guidelines for Cardiopulmonary Resuscitation and Emergency Cardiovascular Care set a goal for the emergency department arrival to treatment time of 1 hour. ${ }^{18}$ The primary complication of treating patients with IV-tPA for acute

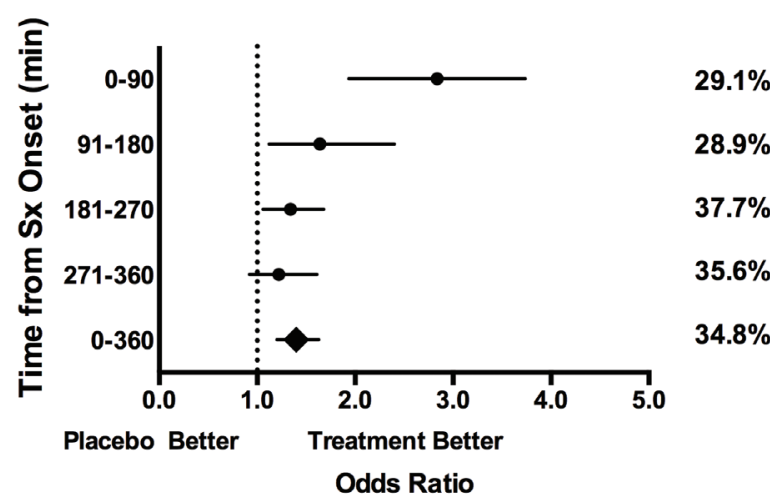

$41.6 \%$

$41.9 \%$

$44.6 \%$

$37.4 \%$

$41.6 \%$

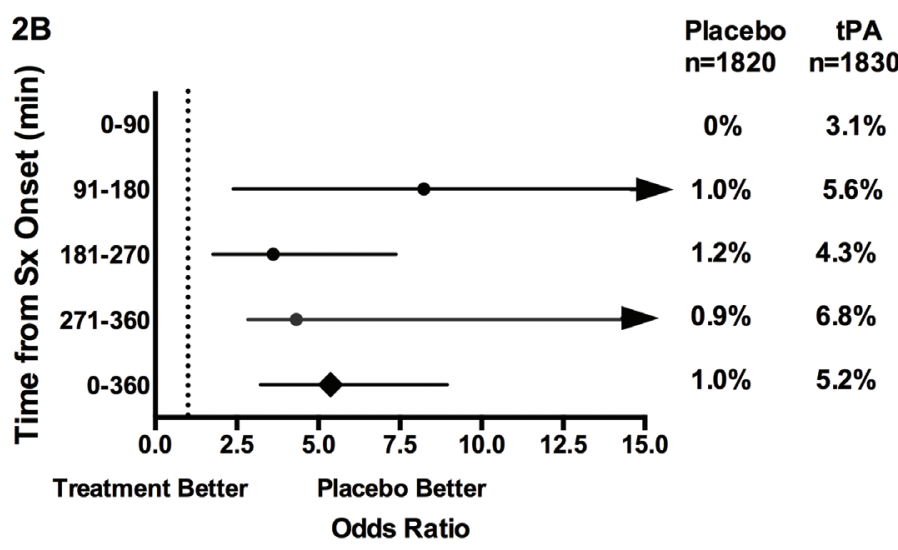

Figure 2. Effect of IV-tPA administration on outcome in patients with acute ischemic stroke based on time between symptom onset and treatment (adjusted for baseline NIH Stroke Scale score [NIHSSS], age, diastolic blood pressure, prior hypertension, prior stroke, and interaction of age and NIHSSS). (A) Effect of treatment on having no disability after 90 days (modified Rankin score 0-1). (B) Effect of treatment on having a parenchymal hemorrhage within 36 hours (adjusted for baseline NIHSSS, age, and diastolic blood pressure). Data from Lees et al. ${ }^{17} \mathrm{IV}$-tPA: intravenous tissue plasminogen activator (alteplase).

ischemic stroke is brain hemorrhage. In the pooled analysis, large intracranial hemorrhage occurred in $5.2 \%$ of patients in the IV-tPA group versus $1.0 \%$ of controls (OR 5.37, 95\% CI, 3.22-8.95). ${ }^{17}$ There was no significant relationship between bleeding risk and time between symptom onset and treatment up to 6 hours (Figure 2B).

Recent national guidelines provide detailed inclusion and exclusion criteria for selecting patients for treatment with IV-tPA, ${ }^{2}$ but a few points should be emphasized. Although ideally only patients with acute ischemic stroke should be given IV-tPA, patients with an ischemic stroke mimic may sometimes be treated due to difficulties in diagnosis. In these cases, administration of IV-tPA does not carry untoward risk provided that treatment inclusion and exclusion criteria are otherwise observed. ${ }^{19}$ Patients with what may be considered mild symptoms can have significantly impaired quality of life and should be considered for treatment. ${ }^{20,21}$ In the absence of a history or findings on examination suggestive of a coagulopathy or the use of anticoagulants, it is not necessary to delay treatment until the results of relevant blood tests are available. ${ }^{2}$

Endovascular treatment of patients with acute stroke may 
involve intra-arterial infusion of a thrombolytic agent (most commonly tPA) and/or use of a mechanical clot retrieval device (FDA-approved as tools to remove clots from brain arteries but not as treatments for acute stroke)—a treatment associated with favorable results compared to placebo or no intervention in selected patients. ${ }^{22}$ The SYNTHESIS Expansion trial compared a strategy of primary endovascular intervention versus IV-tPA in patients with acute ischemic stroke, with the underlying hypothesis that direct treatment of a thrombus would lead to better outcomes. ${ }^{23}$ The trial found that primary endovascular therapy was not superior to IV-tPA (30.4\% in the endovascular therapy group and $34.8 \%$ in the IV-tPA group were alive without disability after 3 months; adjusted OR 0.71, 95\% CI, 0.44-1.14, P = 0.16 ; fatal or nonfatal symptomatic intracranial hemorrhage within 7 days occurred in $6 \%$ of the patients in each group).

"Rescue" endovascular therapy in patients not having an immediate clinical response to treatment with IV-tPA has also been advocated. It should be noted, however, that although patients treated with IV-tPA in the landmark National Institute of Neurological Disorders and Stroke trial more frequently had little or no disability compared to those treated with placebo after 3 months, there was no effect on neurologic impairment after 24 hours. ${ }^{24}$ In addition, observational studies suggest that strokes related to a large clot burden (e.g., proximal middle cerebral artery or intracranial carotid bifurcation ["carotid-T"] occlusions) may be relatively refractory to lysis with IV-tPA. ${ }^{25,26}$ Because patient outcomes are thought to be better if rapid recanalization can be obtained, 27 "rescue" endovascular therapy has also been advocated for those with a persistent radiographic occlusion immediately after receiving IV-tPA. The Interventional Management of StrokeIII (IMS-III) trial evaluated the effect of additional endovascular therapy in patients with an acute ischemic stroke who had received IV-tPA within 3 hours of symptom onset. ${ }^{28}$ Although the study found no important safety issues, the proportions of patients who were functionally independent after 3 months were similar in the two groups $(40.8 \%$ treated with endovascular therapy vs. $38.7 \%$ treated with IV-tPA alone; absolute adjusted difference $1.5 \%, 95 \%$ CI, $6.1 \%-9.1 \%$ ). There was also no difference in those with more severe strokes who were thought to likely have more proximal occlusions. The lack of clinical benefit occurred despite an estimated $40 \%$ greater revascularization rate with the addition of endovascular therapy. This discrepancy between reperfusion and recanalization is consistent with other observations showing a stronger association between good clinical outcome and radiographic markers of reperfusion compared to recanalization. ${ }^{29}$

Clinical trials show that the benefit of IV-tPA is in part dependent on the time between symptom onset and treatment (Figure 2A). This is reflected in the previously cited national guidelines and FDA approval of IV-tPA, with symptom onset taken as the last time the patient was known to be well. MRI and CT studies can be used to show the relative volumes of ischemic, potentially salvageable, and infarcted tissue. Basing treatment decisions on radiographic criteria evaluating the extent of the ischemic penumbra holds promise, especially among those with stroke symptoms beginning after 4.5-hours, including those awakening in the morning having had a stroke while asleep. ${ }^{30,31}$ The MR RESCUE (Mechanical Retrieval and Recanalization of Stroke Clots Using Embolectomy) trial is the most recent evaluating the use of MRI- or CT-based markers of the ischemic penumbra to select patients for reperfusion therapy. ${ }^{32}$ This phase IIb, controlled, open-label (blinded outcome assessment), multicenter trial randomized patients with an acute anterior circulation ischemic stroke to standard care (including IV-tPA as appropriate) or endovascular embolectomy in addition to standard care based on whether the patient had a favorable radiographic penumbral pattern (i.e., relatively large volume of salvageable compared to infarcted tissue) or a nonpenumbral pattern (i.e., relatively large amount of infarcted tissue with a small or no penumbra). After 3 months, there was no overall difference between those who were or were not treated with embolectomy in addition to standard therapy and no difference in the effect of embolectomy based on the presence or absence of a favorable penumbral pattern. Thus, the trial found that selecting patients for embolectomy based on neuroimaging that indicated the presence of a penumbra was not useful. Additional studies using "penumbral imaging" are in progress.

The SYNTHESIS Expansion trial, IMS-III, and MR RESCUE have been the subjects of extensive discussion and critique. For example, the SYNTHESIS Expansion trial did not select patients for endovascular therapy based on the presence of a radiographic (MR or CT angiography) proximal occlusion. The use of a stent clot retriever was found to result in better recanalization rates and better clinical outcomes compared to an older "corkscrew" retriever, ${ }^{33}$ but the older device could be used in both IMS-III and MR RESCUE. Based on the results of the SYNTHESIS Expansion trial and given its higher costs and limited availability, at this time endovascular interventions should generally not be used instead of IV-tPA in patients who qualify for that treatment. ${ }^{2}$ Although not FDA-approved as a treatment for acute stroke, endovascular treatment is reasonable to consider in patients with specific contraindications for IV-tPA, such as having undergone recent surgery (Figure 1). ${ }^{2}$ At this point, evidence of clinical benefit from prospective, randomized, controlled trials of "rescue" endovascular therapy and of patient selection for embolectomy based on imaging of a "favorable" penumbral pattern are lacking, and the approaches should be considered investigational.

\section{General Measures}

Regardless of whether or not a patient is treated with IV-tPA or endovascular therapy, additional management is aimed at providing general medical care, preventing complications, and optimizing functional recovery (Figure 1).

In terms of general care, in the absence of a specific contraindication, patients with acute ischemic stroke should be treated with a platelet antiaggregant within 48 hours of symptom onset (delayed for 24 hours in those treated with IV-tPA). ${ }^{2}$ Treatment with aspirin is associated with nine fewer deaths and nonfatal strokes over the ensuing few weeks per 1,000 persons treated $(\mathrm{P}=0.001) .{ }^{34}$ Comparable data for platelet antiaggregants other than aspirin are generally unavailable. The Clopidogrel in High-Risk Patients with Acute Non-disabling Cerebrovascular Events (CHANCE) trial compared clopidogrel plus aspirin versus aspirin alone started within 24 hours and continued for 21 days in Chinese patients with minor ischemic stroke or TIA. ${ }^{35}$ Over 90 days, $8.2 \%$ of patients in the clopidogrel-plus-aspirin group as compared to $11.7 \%$ in the aspirin-only group had a stroke (HR 0.68, 95\% CI, 0.57-0.81, P < 0.001). A companion study (the POINT trial) is being conducted in the United States. If the results are similar, the combination may replace aspirin for short-term treatment after minor stroke or high-risk TIA. The combination is contraindicated for long-term use for secondary stroke prevention due to a higher risk of bleeding with no reduction in ischemic events compared 
to monotherapy. ${ }^{36,37}$ The emergent use of anticoagulants is not recommended to improve patient outcomes, halt neurologic worsening, or lessen the risk of early recurrent stroke. ${ }^{2}$

Fever in patients with an acute ischemic stroke is associated with poorer outcome. ${ }^{38} \mathrm{~A}$ phase-III trial evaluated the effect of prophylactic acetaminophen in patients with acute ischemic stroke but was stopped early because of a lack of funding. ${ }^{39}$ It is, however, reasonable to treat fever aggressively in patients with acute cerebral ischemia. The use of therapeutic hypothermia to improve patient outcomes after acute ischemic stroke remains investigational. ${ }^{2}$

Owing to a lack of data, blood pressure management in the setting of acute ischemic stroke remains controversial, with current recommendations largely empiric. ${ }^{40}$ At least one trial found that lowering blood pressure in the acute setting was associated with poorer clinical outcomes. ${ }^{41}$ Because of concern about reducing perfusion to an already ischemic brain, "permissive hypertension" (goal less than 220/120 mm Hg) in the absence of another medical condition warranting treatment is recommended over the first 24 hours. ${ }^{2}$ One exception is patients who are otherwise candidates for IV-tPA and whose blood pressure can be lowered to less than 185/110 $\mathrm{mm} \mathrm{Hg}$ and maintained at or below 180/105 mm Hg after treatment. $^{2}$ The optimal time to start antihypertensive treatment after acute stroke is also uncertain. Based on available data, starting after 24 hours is reasonable. ${ }^{2}$

Treating patients who have experienced a noncardioembolic stroke with a high-potency statin reduces the risk of recurrent events, but the impact on functional outcome is less certain. ${ }^{42}$ Both a randomized trial and observational data indicate that stopping a statin in the acute setting is associated with poorer outcomes compared to maintaining statin therapy. ${ }^{43,44}$ Other aspects of the general care of patients with acute stroke are reviewed in current guidelines. $^{2}$

\section{Acute Complications, Secondary Prevention, and Recovery}

Medical complications occur in $30 \%$ to $60 \%$ of patients after an acute ischemic stroke. ${ }^{45}$ Pulmonary and urinary tract infections and deep vein thrombosis are among the more common. Obtaining a swallowing evaluation prior to oral medications and nutrition, avoiding placement and early removal of indwelling bladder catheters, and use of mechanical and pharmacologic prophylaxes for deep vein thrombosis can decrease the likelihood of these complications. ${ }^{2}$

Approximately $20 \%$ of strokes are recurrent events. Effective secondary prevention depends on management of general stroke risk factors (e.g., hypertension, hyperlipidemia, obesity, smoking cessation) and identification of specific conditions that could have caused the stroke (e.g., atrial fibrillation, carotid stenosis). The management of these and other potential causes of stroke are reviewed in current secondary prevention guidelines. ${ }^{46}$

The process of recovery begins as soon as the patient is stabilized. Although techniques vary, multidisciplinary rehabilitation is associated with improved functional outcome after stroke (five extra patients returned home in an independent state for every 100 treated), including reductions in death $(\mathrm{OR}=0.66$, $95 \% \mathrm{CI}, 0.49-0.88)$, death or institutionalization $(\mathrm{OR}=0.70,95 \% \mathrm{CI}$, $0.56-0.88)$, and death or dependency $(\mathrm{OR}=0.65,95 \% \mathrm{CI}, 0.50-0.85) .{ }^{47}$
The frequency of post-stroke depression varies among studies, depending on diagnostic criteria and the characteristics of the study cohort. ${ }^{48}$ One prospective study found that $10 \%$ to $20 \%$ of patients were depressed 3 months after stroke. ${ }^{48}$ Recognition of depression is important as it contributes to post-stroke morbidity and is frequently undertreated. ${ }^{48}$ At least one study found that treatment with fluoxetine led to improved functional outcome after stroke. $^{49}$

\section{Conclusion}

The modern medical management of patients with acute ischemic stroke is complex, and this report reviewed only the highlights. Detailed, evidence-based recommendations for acute treatment and secondary prevention can be obtained from the cited American Heart Association guidelines.

Conflict of Interest Disclosure: The author has been a consultant for Pfizer.

Funding/Support: The author has received honoraria as a speaker at a Pfizer educational meeting.

Keywords: ischemic stroke; reperfusion; complications; blood pressure; platelet antiaggregants; fever; depression

\section{References}

1. Schwamm LH, Pancioli A, Acker JE 3rd, Goldstein LB, Zorowitz RD, Shephard TJ, et al. Recommendations for the establishment of stroke systems of care: recommendations from the American Stroke Association's Task Force on the Development of Stroke Systems. Circulation. 2005 Mar 1;111(8):1078-91.

2. Jauch EC, Saver JL, Adams HP Jr, Bruno A, Connors JJ, Demaerschalk BM, et al. Guidelines for the early management of patients with acute ischemic stroke: A guideline for healthcare professionals from the American Heart Association/ American Stroke Association. Stroke. 2013 Jan 31;44:870-947.

3. Alberts MJ, Hademenos G, Latchaw RE, Jagoda A, Marler JR, Mayberg MR, et al. Recommendations for the establishment of primary stroke centers. Brain Attack Coalition. JAMA. 2000 Jun 21;283(23):3102-9.

4. Alberts MJ, Latchaw RE, Selman WR, Shephard T, Hadley $M N$, Brass LM, et al. Recommendations for comprehensive stroke centers - a consensus statement from the Brain Attack Coalition. Stroke. 2005 Jul;36(7):1597-616.

5. Lichtman JH, Jones SB, Leifheit-Limson EC, Wang Y, Goldstein LB. 30-day mortality and readmission after hemorrhagic stroke among Medicare beneficiaries in Joint Commission primary stroke center-certified and noncertified hospitals. Stroke. 2011 Dec;42(12):3387-91.

6. Lichtman JH, Jones SB, Wang Y, Watanabe E, Leifheit-Limson EC, Goldstein LB. Outcomes after ischemic stroke for hospitals with and without Joint Commission-certified primary stroke centers. Neurology. 2011 Jun 7;76(23):1976-82.

7. Xian Y, Holloway RG, Chan PS, Noyes K, Shah MN, Ting HH, et al. Association between stroke center hospitalization for acute ischemic stroke and mortality. JAMA. 2011 Jan 26;305(4): 373-80.

8. Fonarow GC, Reeves MJ, Smith EE, Saver JL, Zhao X, Olson DW, et al. Characteristics, performance measures, and in-hospital outcomes of the first one million stroke and transient ischemic attack admissions in Get With the Guidelines-Stroke. Circulaion Cardiovascular Quality and Outcomes. 2010 Feb 22;3:291-302. 
9. Goldstein LB, Simel DL. Is this patient having a stroke? JAMA. 2005 May 18;293(19):2391-402.

10. Jerath NU, Reddy C, Freeman WD, Jerath AU, Brown RD. Gender differences in presenting signs and symptoms of acute ischemic stroke: a population-based study. Gend Med. 2011 Oct;8(5):312-9.

11. Lisabeth LD, Brown DL, Hughes R, Majersik JJ, Morgenstern LB. Acute stroke symptoms: comparing women and men. Stroke. 2009 Jun;40(6):2031-6.

12. Hand PJ, Kwan J, Lindley RI, Dennis MS, Wardlaw JM. Distinguishing between stroke and mimic at the bedside: the brain attack study. Stroke. 2006 Mar;37(3):769-75.

13. Goldstein LB. Stroke code chest radiographs are not useful. Cerebrovasc. Dis. 2007;24(5):460-2.

14. Saposnik G, Cote R, Mamdani M, Raptis S, Thorpe KE, Fang J, et al. JURaSSiC: accuracy of clinician vs risk score prediction of ischemic stroke outcomes. Neurology. 2013 Jul 30;81(5): 448-55.

15. Brott T, Adams HP Jr, Olinger CP, Marler JR, Barsan WG, Biller $J$, et al. Measurements of acute cerebral infarction: a clinical examination scale. Stroke. 1989 Jul;20(7):864-70.

16. Jones TH, Morawetz RB, Crowell RM, Marcoux FW, FitzGibbon SJ, DeGirolami U, et al. Thresholds of focal cerebral ischemia in awake monkeys. J Neurosurg. 1981 Jun;54(6):773-82.

17. Lees KR, Bluhmki E, von Kummer R, Brott TG, Toni D, Grotta $\mathrm{JC}$, et al. Time to treatment with intravenous alteplase and outcome in stroke: An updated pooled analysis of ECASS, ATLANTIS, NINDS, and EPITHET trials. Lancet. 2010 May 15;375(9727):1695-703.

18. Jauch EC, Cucchiara B, Adeoye O, Meurer W, Brice J, Chan Y, et al. Part 11: adult stroke: 2010 American Heart Association Guidelines for Cardiopulmonary Resuscitation and Emergency Cardiovascular Care. Circulation. 2010 Nov 2;122 (18 Suppl 3):S818-28.

19. Chernyshev OY, Martin-Schild S, Albright KC, Barreto A, Misra V, Acosta I, et al. Safety of tPA in stroke mimics and neuroimaging-negative cerebral ischemia. Neurology. $2010 \mathrm{Apr}$ 27;74(17):1340-5.

20. Duncan PW, Samsa GP, Weinberger M, Goldstein LB, Bonito A, Witter DM, et al. Health status of individuals with mild stroke. Stroke. 1997 Apr;28(4):740-5.

21. Smith EE, Fonarow GC, Reeves MJ, Cox M, Olson DM, Hernandez AF, et al. Outcomes in mild or rapidly improving stroke not treated with intravenous recombinant tissue-type plasminogen activator: findings from Get With The GuidelinesStroke. Stroke. 2011 Nov;42(11):3110-5.

22. Lee M, Hong KS, Saver JL. Efficacy of intra-arterial fibrinolysis for acute ischemic stroke: meta-analysis of randomized controlled trials. Stroke. 2010 May;41(5):932-7.

23. Ciccone A, Valvassori L, Nichelatti M, Sgoifo A, Ponzio M, Sterzi R, et al. Endovascular treatment for acute ischemic stroke. N Engl J Med. 2013 Mar 7;368(10):904-13.

24. Marler JR, Brott T, Broderick J, Kothari R, O'Donoghue $\mathrm{M}$, Barsan W, et al. Tissue plasminogen activator for acute ischemic stroke. N Engl J Med. 1995 Dec 14;333:1581-88.
25. Hirano T, Sasaki M, Mori E, Minematsu K, Nakagawara J, Yamaguchi T. Residual vessel length on magnetic resonance angiography identifies poor responders to alteplase in acute middle cerebral artery occlusion patients: exploratory analysis of the Japan Alteplase Clinical Trial II. Stroke. 2010 Dec;41(12):2828-33.

26. Beck C, Cheng B, Krutzelmann A, Rosenkranz M, Gerloff C, Fiehler J, et al. Outcome of MRI-based intravenous thrombolysis in carotid-T occlusion. J Neurol. 2012 Oct;259(10):2141-6.

27. Rha JH, Saver JL. The impact of recanalization on ischemic stroke outcome: a meta-analysis. Stroke. 2007 Mar;38(3): 967-73.

28. Broderick JP, Palesch YY, Demchuk AM, Yeatts SD, Khatri P, Hill MD, et al.; Interventional Management of Stroke (IMS) III Investigators. Endovascular therapy after intravenous t-PA versus t-PA alone for stroke. N Engl J Med. 2013 Mar 7;368(10):893-903.

29. Eilaghi A, Brooks J, d'Esterre C, Zhang L, Swartz RH, Lee TY, et al. Reperfusion is a stronger predictor of good clinical outcome than recanalization in ischemic stroke. Radiology. 2013 Oct;269(1):240-8.

30. Latchaw RE, Yonas H, Hunter GJ, Yuh WTC, Ueda T, Sorensen $A G$, et al. Guidelines and recommendations for perfusion imaging in cerebral ischemia: A scientific statement for healthcare professionals by the writing group on perfusion imaging, from the Council on Cardiovascular Radiology of the American Heart Association. Stroke. 2003;34:1084-104.

31. Schellinger PD, Bryan RN, Caplan LR, Detre JA, Edelman $\mathrm{RR}$, Jaigobin $\mathrm{C}$, et al. Evidence-based guideline: The role of diffusion and perfusion MRI for the diagnosis of acute ischemic stroke: report of the Therapeutics and Technology Assessment Subcommittee of the American Academy of Neurology. Neurology. 2010 Jul 13;75(2):177-85.

32. Kidwell CS, Jahan R, Gornbein J, Alger JR, Nenov V, Ajani Z, et al. A trial of imaging selection and endovascular treatment for ischemic stroke. N Engl J Med. 2013 Mar 7;368(r10):914-23.

33. Saver JL, Jahan R, Levy El, Jovin TG, Baxter B, Nogueira $R G$, et al. Solitaire flow restoration device versus the Merci Retriever in patients with acute ischaemic stroke (SWIFT): a randomised, parallel-group, non-inferiority trial. Lancet. 2012 Oct 6;380(9849):1241-9.

34. CAST: randomised placebo-controlled trial of early aspirin use in 20000 patients with acute ischaemic stroke. CAST (Chinese Acute Stroke Trial) Collaborative Group. Lancet. 1997 Jun 7;349(9066):1641-9.

35. Wang Y, Wang Y, Zhao X, Liu L, Wang D, Wang C, et al.: CHANCE Investigators. Clopidogrel with aspirin in acute minor stroke or transient ischemic attack. N Engl J Med. 2013 Jul 4;369(1):11-9.

36. Diener HC, Bogousslavsky J, Brass LM, Cimminiello C, Csiba L, Kaste M, et al. Aspirin and clopidogrel compared with clopidogrel alone after recent ischaemic stroke or transient ischaemic attack in high-risk patients $(\mathrm{MATCH})$ : randomised, double-blind, placebo-controlled trial. Lancet. $2004 \mathrm{Jul}$ 24-30;364(9431):331-7.

37. The SPS3 Investigators, Benavente OR, Hart RG, McClure LA Szychowski JM, Coffey CS, et al. Effects of clopidogrel added to aspirin in patients with recent lacunar stroke. N Engl J Med. 2012 Aug 30;367(9):817-25. 
38. Prasad K, Krishnan PR. Fever is associated with doubling of odds of short-term mortality in ischemic stroke: an updated meta-analysis. Acta Neurol Scand. 2010 Dec;122(6):404-8.

39. den Hertog HM, van der Worp HB, van Gemert HM, Algra A, Kappelle LJ, van Giin J, et al. The Paracetamol (Acetaminophen) In Stroke (PAIS) trial: a multicentre, randomised, placebo-controlled, phase III trial. Lancet Neurol. 2009 May;8(5):434-40.

40. Goldstein LB. Blood pressure management in patients with acute ischemic stroke. Hypertension. 2004 Feb;43(2):137-41.

41. Ahmed N, Nasman P, Wahlgren NG. Effect of intravenous nimodipine on blood pressure and outcome after acute stroke. Stroke. 2000 Jun;31(6):1250-5.

42. Goldstein LB. Statins and ischemic stroke severity: cytoprotection. Curr Atheroscler Rep. 2009 Jul;11(4):296-300.

43. Blanco M, Nombela F, Castellanos M, Rodriguez-Yáñez M, Garcia-Gil M, Leira R, et al. Statin treatment withdrawal in ischemic stroke: a controlled randomized study. Neurology. 2007 Aug 28;69(9):904-10.

44. Flint AC, Kamel H, Navi BB, Rao VA, Faigeles BS, Conell C, et al. Statin use during ischemic stroke hospitalization is strongly associated with improved poststroke survival. Stroke. 2012 Jan;43(1):147-54.
45. Kumar S, Selim MH, Caplan LR. Medical complications after stroke. Lancet Neurol. 2010 Jan;9(1):105-18.

46. Furie KL, Kasner SE, Adams RJ, Albers GW, Bush RL, Fagan SC, et al.; American Heart Association Stroke Council, Council on Cardiovascular Nursing, Council on Clinical Cardiology, and Interdisciplinary Council on Quality of Care and Outcomes Research. Guidelines for the prevention of stroke in patients with stroke or transient ischemic attack: a guideline for healthcare professionals from the American Heart Association/ American Stroke Association. Stroke. 2011 Jan;42(1):227-76.

47. Langhorne P, Duncan P. Does the organization of postacute stroke care really matter? Stroke. 2001 Jan;32(1):268-74.

48. El Husseini N, Goldstein LB, Peterson ED, Zhao X, Pan W, Olson DM, et al. Depression and antidepressant use after stroke and transient ischemic attack. Stroke. 2012 Jan;43(6):1609-16.

49. Chollet F, Tardy J, Albucher JF, Thalamas C, Berard E, Lamy C, et al. Fluoxetine for motor recovery after acute ischaemic stroke (FLAME): a randomised placebo-controlled trial. Lancet Neurol. 2011 Feb;10(2):123-30. 